\title{
Overcoming blame culture: Key strategies to catalyze Maternal and Perinatal Death Surveillance and Response
}

Mary Kinney ${ }^{1}$, Louise TinaDay ${ }^{2}$, Francesca Palestra ${ }^{3}$, Animesh Biswas ${ }^{4}$, Debra Jackson ${ }^{2}$, Nathalie Roos ${ }^{5}$, Ank Jonge ${ }^{6}$, Patricia Doherty ${ }^{7}$, Alexander Manu ${ }^{8}$, Allisyn Moran ${ }^{3}$, and Asha George ${ }^{1}$

${ }^{1}$ University of the Western Cape School of Public Health

${ }^{2}$ London School of Hygiene and Tropical Medicine Centre for Maternal Adolescent Reproductive and Child Health

${ }^{3}$ World Health Organization

${ }^{4}$ Centre for Injury Prevention and Research Bangladesh

${ }^{5}$ Karolinska Institutet

${ }^{6}$ Amsterdam University Medical Centres

${ }^{7}$ Options Consultancy Services Ltd

${ }^{8}$ University of Ghana School of Public Health

September 24, 2021

\section{Hosted file}

BJOG commentary on blame culture for submission.docx available at https://authorea.com/users/ 435656/articles/538527-overcoming-blame-culture-key-strategies-to-catalyze-maternal-andperinatal-death-surveillance-and-response 


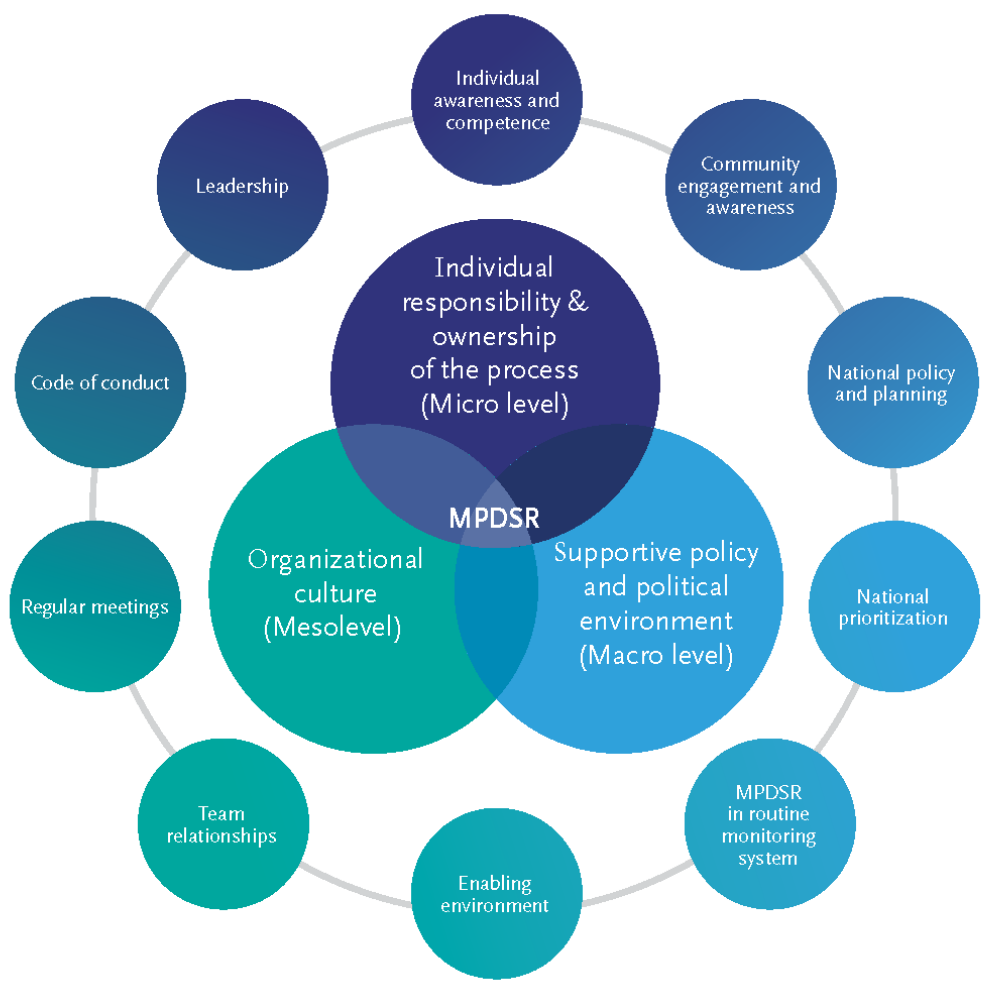

